\section{(C) \\ OPEN ACCESS}

\title{
Fulminant myocardial bleeding: another clinical course of vascular Ehlers-Danlos Syndrome
}

\author{
Masahide Tokue, ${ }^{1}$ Hidehiko Hara, ${ }^{1}$ Kenji Kurosawa, ${ }^{2}$ Masato Nakamura ${ }^{1}$
}

\begin{abstract}
${ }^{1}$ Department of Cariovascular Medicine, Toho University Ohashi Medical Center, Tokyo, Japan

${ }^{2}$ Department of Medical Genetics, Kanagawa Children's Medical Center, Yokohama, Japan
\end{abstract}

\section{Correspondence to}

Dr Masahide Tokue, masahide.tokue@med.toho-u. ac.jp

Accepted 2 September 2017

\section{SUMMARY}

Vascular Ehlers-Danlos Syndrome (vEDS) is a dominantly inherited connective tissue disorder characterised by colon rupture and arterial aneurysm, dissection and rupture. A patient was diagnosed with vEDS after a spontaneous colon rupture when he was brought to our institute because of sudden chest pain. An ECG revealed wide regional ST elevation, which was initially suggestive of acute myocarditis. On the second day, haemodynamics suddenly deteriorated because of a rapid accumulation of bloody pericardial effusion, and the patient died. Autopsy revealed an excessive spontaneous myocardial haemorrhage owing to fragility, which suggested an underlying disease-vEDS

\section{BACKGROUND}

Cases of fulminant myocardial bleeding and ischaemia are not frequently reported. To the best of our knowledge, only one fatal case of myocardial bleeding due to vascular Ehlers-Danlos Syndrome (vEDS) has been reported in the literature. ${ }^{1}$ However, because it was a postmortem case, the clinical course of vEDS remained unknown.

\section{CASE PRESENTATION}

A 30-year-old man with chest pain was referred to our institute. He underwent repeated surgeries for spontaneous colon rupture. Five years after the surgeries, he was diagnosed with vEDS. His sister also underwent surgical repair due to arterial rupture. A novel heterozygous mutation at the donor-splice site in intron 23 (IVS23+1G $>$ A) in the COL $3 A 1$ gene was detected in the patient.

\section{INVESTIGATION}

On presentation to the emergency room, the patient's blood pressure was $98 / 60 \mathrm{~mm} \mathrm{Hg}$ in both

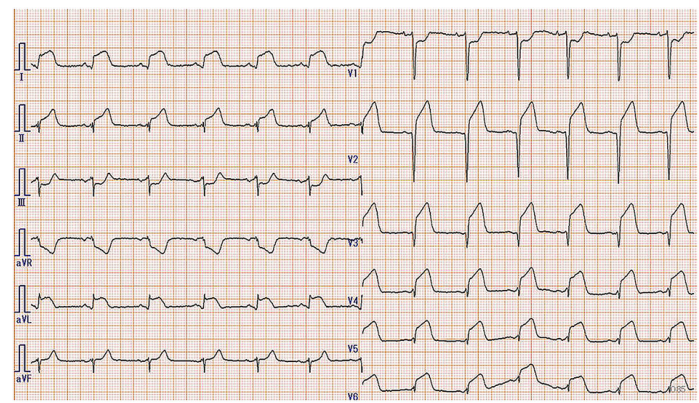

Figure 1 ST segment elevation in I, aVL, II and V2-6.

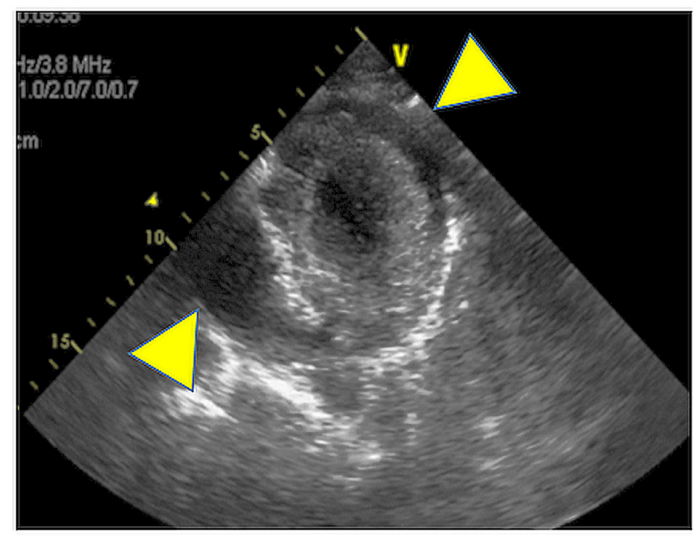

Figure 2 Transthoracic echocardiography (short-axis view) showing massive pericardial effusion (arrowheads).

arms. A physical examination revealed pallor, thin translucent skin and absence of heart murmur. An ECG showed a wide range of ST elevation (figure 1). Laboratory data revealed higher levels of troponin T and creatine kinase. An emergency coronary angiogram revealed no significant stenosis. Left ventriculography showed severe hypokinesis of segments 2 and 3. After admission to the intensive care unit, the patient suddenly suffered from cardiogenic shock due to cardiac tamponade (figure 2). No evidence of aortic aneurysm or dissection was documented by CT. Pericardiocentesis was performed, and a haemorrhagic effusion of $250 \mathrm{~mL}$ was identified. Percutaneous cardiopulmonary support was introduced because the patient showed sudden haemodynamic deterioration despite pericardiocentesis. Cardiopulmonary support was discontinued on the following day because the patient's haemodynamics stabilised and left ventricular wall motion improved. However, persistent ventricular fibrillation occurred, and the patient died 48 hours after admission. Autopsy revealed multiple epicardial and significant intramyocardial haemorrhages in all areas of the myocardial wall (figure 3); however, there were no significant findings in the coronary tree. Histopathological results revealed acute, widespread and generalised haemorrhages in the intramuscular layer and scattered myocardial lesions throughout myocardial walls without inflammatory cell infiltration (figure 4). There was no rupture or dissection in vessel walls; however, type 3 collagen tissues around vessel walls showed a thinner structure (figure 5). 


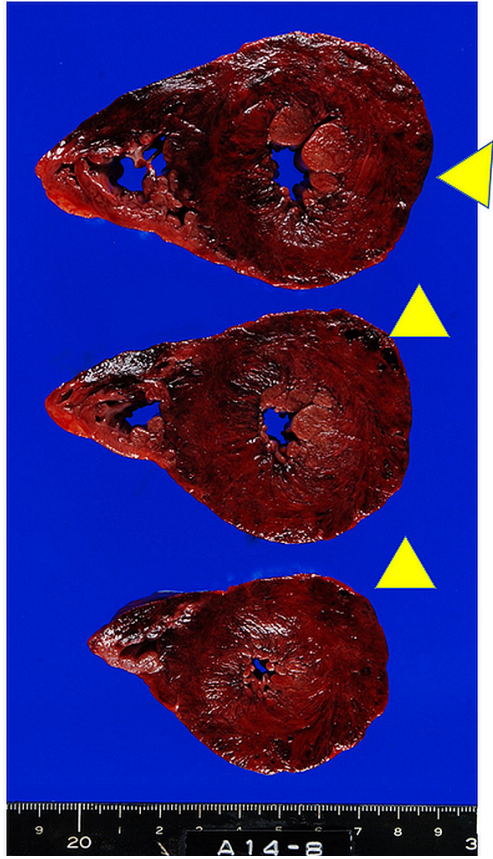

Figure 3 Gross pathological findings including diffuse hypertrophic lesions with multiple points of bleeding (arrowheads).

\section{DIFFERENTIAL DIAGNOSIS}

The described clinical manifestations were compatible with progressive cardiogenic shock due to acute myocarditis, acute myocardial infarction or aortic dissection leading to cardiac tamponade and arrest. ECG findings indicated wide regional ST segment elevation, which indicated the presence of coronary artery disease. Coronary angiogram showed no evidence of acute coronary syndrome. Pericardiocentesis was then performed to treat cardiac tamponade. No evidence of aortic dissection or aneurysmal rupture was shown in the CT scan. We could not identify the clinical issue for differential diagnosis. Intramyocardial haemorrhages were finally identified in the autopsy.

\section{DISCUSSION}

Over two decades, the new international classification of EDS recognised 13 subtypes, which normally included all phenotypes presenting basic clinical hallmarks of EDS. ${ }^{2}$ Of these subtypes, vEDS is an autosomal dominant hereditary connective tissue

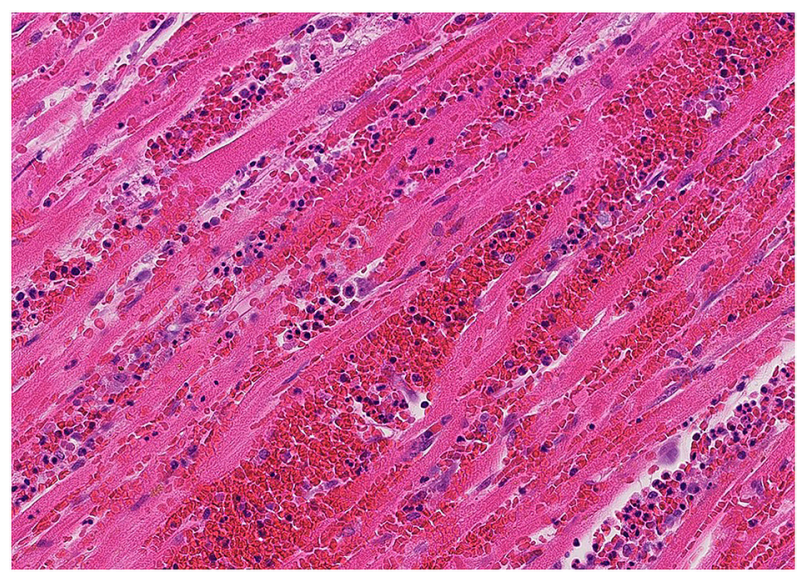

Figure 4 Fragmentation of intramyocardial haemorrhage in myocardial tissues (H\&E stain, $\times 200$ ).

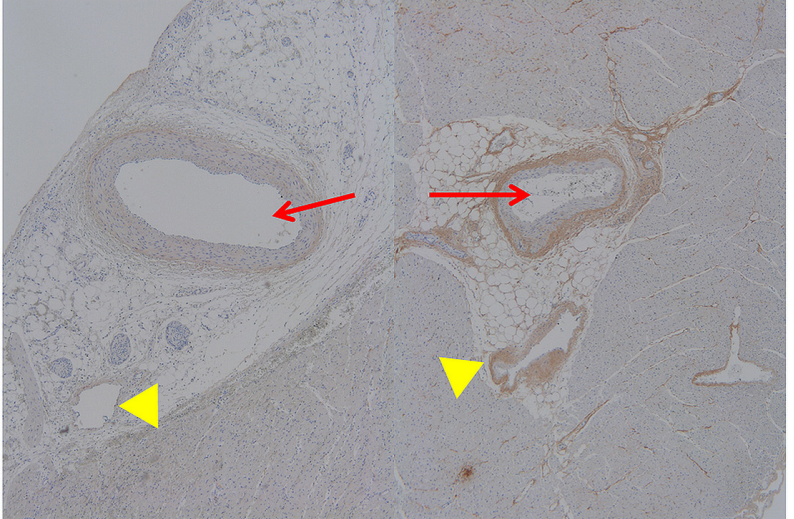

Figure 5 Microscopic examination of intramyocardial arterial (arrows) and venous (arrowheads) walls revealed that the amount of type 3 collagen was extremely low in our patient (left) than in the control (right) ( $\times$ type 3 elastic-specific staining).

disorder caused by a structural defect in the pro $\alpha$ (1) chain of type 3 collagen encoded by COL3A1. Extensive bruising, spontaneous arterial rupture and a typical facial appearance are the predominant clinical manifestations. ${ }^{3}{ }^{4}$ The cause of death is generally an accidental large arterial rupture. Major arterial complications related to a COL5A1 mutation have also been reported. ${ }^{5}$ Type 3 collagen is a major protein in the walls of blood vessels and hollow organs, which explains the increased bruising, arterial and bowel fragilities and uterine, cervical and vaginal fragilities during pregnancy and delivery. ${ }^{6}$ This mutation can either cause decreased or no collagen synthesis or abnormalities in collagen secretion. ${ }^{78}$ Approximately, 50\% of affected individuals have inherited the COL $3 A 1$ mutation from an affected parent, while the other $50 \%$ have a de novo disease caused by a new onset of mutation. ${ }^{9}$ This case was identified in the COL3A1 of the patient; however, Sanger sequence analysis confirmed that the apparently normal parents had no mutation. It is difficult to accurately assess the prevalence of vEDS, partly because of its rarity. A diagnosis is often made only after a catastrophic complication or during autopsy. Notably, the previously reported case is similar to the present case with respect to the sudden onset of symptoms and haemorrhage of intramyocardial capillary vessels. Although the aetiology is unclear, the spontaneous rupture of large arteries is typically associated with a fatal outcome caused by the fragility of blood vessels in vEDS. Previous studies have reported that CAG causes fatal damages of friable vessels characterised by multiple dissection. ${ }^{10}$ Autopsy revealed that the spontaneous haemorrhage of multiple intramyocardial capillary vessels resulted in a fatal outcome. There was no injury

\section{Learning points}

- This is the first reported case of catastrophic clinical manifestations due to myocardial bleeding without coronary artery disease in a patient with vascular Ehlers-Danlos Syndrome (vEDS).

- Skin elasticity may be the key for diagnosis, which can be identified during physical examination.

- Invasive examination should be performed with more consideration in the management of vEDS.

- This is a remarkable case in which vEDS is diagnosed from a patient with normal parents without gene mutation. 
in any large vessels; therefore, this is an extremely rare cause of death. Notably, the fragility of small vessel walls may be associated with the haemorrhage of capillary vessels. Otherwise, there might be multiple vascular dissections that are not microscopically detected. Defects of the supporting type 3 connective tissue and interstitial collagen deficiency in small heart vessels could represent important issues in patients with vEDS. This has never been detected during the natural course of vEDS, characterised by fulminant myocardial bleeding that causes a tragic outcome in a young adult.

Acknowledgements We are grateful to Professor Kei Takahashi for the examination of the pathological tissue and for his helpful discussion. In addition, we would like to thank Dr Yoshinori Nagashima, Dr Megumi Minakawa and Dr Naohiko Sahara for their tremendous works on the management of the patient.

Contributors MT is the first author and the corresponding author too. HH was responsible for reviewing article and performed emergent coronary angiogram. KK was involved in the genetic screening. $\mathrm{MN}$ was responsible for the final approval of the version to be submitted.

Competing interests None declared.

Patient consent Obtained from guardian.

Provenance and peer review Not commissioned; externally peer reviewed.

Open Access This is an Open Access article distributed in accordance with the Creative Commons Attribution Non Commercial (CC BY-NC 4.0) license, which permits others to distribute, remix, adapt, build upon this work non-commercially, and license their derivative works on different terms, provided the original work is properly cited and the use is non-commercial. See: http://creativecommons.org/ licenses/by-nc/4.0/

(c) BMJ Publishing Group Ltd (unless otherwise stated in the text of the article) 2017. All rights reserved. No commercial use is permitted unless otherwise expressly granted.

\section{REFERENCES}

1 Escribano N, Medina I, Ortega L, et al. The role of postmortem study in the diagnosis of the cause of death in a young man: a rare case of Ehlers-Danlos syndrome type IV. Case Rep Child Meml Hosp Chic 2010;2010:bcr1220081395.

2 Malfait F, Francomano C, Byers P, et al. The 2017 international classification of the Ehlers-Danlos syndromes. Am J Med Genet C Semin Med Genet 2017;175:8-26.

3 Steinmann B, Royce PM, Superti-Furga A. The Ehlers-Danlos syndrome. In: Royce PM, Steinmann B, eds. Connective tissue and its heritable disorders. molecular, genetic and medical aspects. New York: Wiley-Liss, 1993.

4 Pope FM, Nicholls AC, Dorling J, et al. Molecular abnormalities of collagen: a review. J R Soc Med 1983;76:1050-62.

5 Borck G, Beighton P, Wilhelm C, et al. Arterial rupture in classic Ehlers-Danlos syndrome with COL5A1 mutation. Am J Med Genet A 2010;152A:2090-3.

6 Byers PH, Belmont J, Black J, et al. Diagnosis, natural history, and management in vascular Ehlers-Danlos syndrome. Am I Med Genet C Semin Med Genet 2017;175:40-7.

7 Byers PH, Holbrook KA, McGillivray B, et al. Clinical and ultrastructural heterogeneity of type IV Ehlers-Danlos syndrome. Hum Genet 1979;47:141-50.

8 Pope FM, Nicholls AC, Narcisi P, et al. Type III collagen mutations in Ehlers Danlos syndrome type IV and other related disorders. Clin Exp Dermatol 1988:13:285-302.

9 Pepin M, Byers P. Ehlers-Danlos syndrome vascular type. Gene Rev 1999.

10 Kimura K, Sakai-Kimura M, Takahashi R, et al. Too friable to treat? Lancet 2010;375:1578.

Copyright 2017 BMJ Publishing Group. All rights reserved. For permission to reuse any of this content visit

http://group.bmj.com/group/rights-licensing/permissions.

BMJ Case Report Fellows may re-use this article for personal use and teaching without any further permission.

Become a Fellow of BMJ Case Reports today and you can:

- Submit as many cases as you like

- Enjoy fast sympathetic peer review and rapid publication of accepted articles

- Access all the published articles

Re-use any of the published material for personal use and teaching without further permission

For information on Institutional Fellowships contact consortiasales@bmjgroup.com

Visit casereports.bmi.com for more articles like this and to become a Fellow 